\title{
Article \\ Design and Development of a Climbing Robot for Wind Turbine Maintenance
}

\author{
Jui-Hung Liu 1,*(D) and Kathleen Padrigalan ${ }^{2}$ \\ 1 Department of Mechanical Engineering, Southern Taiwan University of Science and Technology, No. 1, \\ Nan-Tai Street, Yungkang District, Tainan City 710301, Taiwan \\ 2 College of Technology, University of Science and Technology of Southern Philippines, C.M. Recto Avenue, \\ Lapasan, Cagayan de Oro City 9000, Philippines; da81y202@stust.edu.tw \\ * Correspondence: dofliu@stust.edu.tw; Tel.: +886-913233353
}

check for updates

Citation: Liu, J.-H.; Padrigalan, K. Design and Development of a Climbing Robot for Wind Turbine Maintenance. Appl. Sci. 2021, 11, 2328. https://doi.org/10.3390/ app11052328

Academic Editor: Oscar

Reinoso Garcia

Received: 14 January 2021

Accepted: 1 March 2021

Published: 5 March 2021

Publisher's Note: MDPI stays neutral with regard to jurisdictional claims in published maps and institutional affiliations.

Copyright: (c) 2021 by the authors. Licensee MDPI, Basel, Switzerland. This article is an open access article distributed under the terms and conditions of the Creative Commons Attribution (CC BY) license (https:// creativecommons.org/licenses/by/ $4.0 /)$.

\begin{abstract}
The evolution of the wind turbine to generate carbon-free renewable energy is rapidly growing. Thus, performing maintenance and inspection tasks in high altitude environments or difficult to access places, and even bad weather conditions, poses a problem for the periodic inspection process of the wind turbine industry. This paper describes the design and development of a scaleddown prototype climbing robot for wind turbine maintenance to perform critical tower operations. Thus, the unique feature of this maintenance robot is the winding mechanism, which uses a tension force to grip on the tower surface without falling to the ground either in static or dynamic situations, with the locomotion to perform a straight up-down motion in a circular truncated cone and the stability to work at significant heights. The robot computer-aided design (CAD) model of the mechanical mechanism, force and structural analysis, and the testing of the prototype model, are addressed in this paper. The key hardware developments that were utilized to build a low-cost, reliable and compact climbing robot are the embedded microprocessors, brushed DC motors, stepper motors and steel rope. This paper concludes with a successful preliminary experiment of a scaled down prototype proving the functionality of the concept. The potential applications for this robot are industrial maintenance, inspection and exploration, security and surveillance, cleaning, painting, and welding at extreme height conditions.
\end{abstract}

Keywords: climbing robot; maintenance; circular truncated cone; winding mechanism

\section{Introduction}

Bridges, dams, fuel storage tanks, cargo ships, vessels and onshore/offshore wind turbines are important industrial and economic structures. These complex structures ensure the worldwide distribution of products, energy supply and transportation, which are the foundations of modern life. The evolution of the wind turbine to generate carbon-free renewable energy is in the spotlight now because of the future target development leading to a clean energy technology. Thus, the rapid increase in wind turbine demand extended to a manifold task and will equate to face a different challenge in terms of its operation and maintenance. Like any outdoor surface, wind turbines naturally collect detritus sources such as ice, hail, dust, marine salt, grease, hydraulic oil, UV radiation and flying planktons. These factors affect the performance efficiency or may lead to the failure of wind turbine parts. The wind turbine structure parts, such as towers and rotor blades, still need regular and intense maintenance [1]. Maintenance in wind energy is a challenging task, where climbing such structures tends to be a hazardous job. The wind turbine maintenance remains a manual task, and it is performed by the technical climbers accessing a significant height with a crane or working while hanging down with a rope from a nacelle of the wind turbine, as shown in Figure 1. The inspection personnel may perform simple ground visual inspections, or a close-up tower visual inspection to assess on nominated areas at the different intensities of dirt, corrosion and cracking on the wind turbine parts.Therefore, 
these hazardous tasks are suitable for the climbing robot mission rather than human beings for safety and ease of inspection.

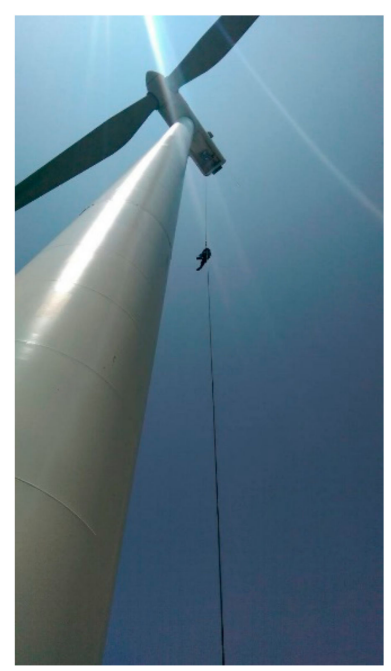

Figure 1. Wind turbine maintenance and working condition

To address the aforementioned issues, the idea of using a climbing robot is the optimum solution to perform tasks that involve a high risk for technical workers who have to climb the wind turbines tower. The development of a climbing robot that can conduct automatic detection and maintenance operations on the wind turbine parts at high altitude, even in a different weather conditions, was the aim of this manuscript. Climbing robots belong to a specialized field of mobile robots designed to safely perform maintenance and inspection. The main feature is mobility against the gravitational pull of the body. In designing these robots, one important aspect to consider is the mechanism of the adhesion that is strong enough to travel upwards with the different diameter and bear its weight. Therefore, the designer should not only consider the robot's locomotion method, as in conventional robots, but also its techniques for sticking to the wind turbine parts.

There are different methods of adhesion initially designed for climbing a specific kind of structure or surface. The first type is magnetic adhesion for climbing on a ferrous surface via electromagnets or permanent magnets [2,3]. The advantage of this form of adhesion is a strong and stable adhesion force; its drawback is that this type of adhesion is limited to only the ferromagnetic structure. The second type is vacuum/air suction adhesion for sticking the robot onto the walls. This adhesion process is stable but is accomplished by using air compressors or some other source of air [4-6]. The drawbacks of suction-based climbing robots are: (1) they need the perfect sealing of the suction cup; and (2) they take time to produce a vacuum and release the suction for locomotion. They can therefore operate only at low speed on smooth and non-porous surfaces (e.g., glass, metal walls, or painted walls). These limitations greatly limit the robots' applications. The third type is mechanical adhesion, which utilizes armed mechanisms or grippers to handle uneven surfaces that are only suitable for uneven and complex structures surfaces such as poles, branches of trees, and rough building surfaces [7-9]. The benefit of this type of adhesion is the ability to ascend on uneven and rough surfaces, but flat and smooth surfaces cannot be climbed. The fourth type is electrostatic adhesion. It can provide adhesion on smooth surfaces, both conductor and insulator. The drawback of this method is that it is only suitable for smooth surfaces, including glass, acrylic, and plastic panels. The electrostatic adhesion can be enhanced by using flexible and soft elastic material as the dielectric to improve its resistance against the peeling force $[10,11]$. The fifth type is propeller-type adhesion attraction force generators, based on aerodynamic principles $[12,13]$. These propeller climbing robots depend only on the thrust force of the propellers as the only source for generating the 
adhesion force, which may cause a problem of stability unless a more sophisticated control technique is used [3].

Climbing robots can be classified into several types in terms of locomotion modes. Wheeled, tracked, legged, or arms with grippers and combined types have been applied in the field of climbing robots $[2,14,15]$. Typically, robots with wheels or tracks are used with few obstacles on continuous surfaces as they have a higher speed than legged climbing robots. The legged or arms climbing method is more applicable than other mechanisms if the surface has a complex structure or irregular obstacles. Robots have different climbing mechanisms, depending on the characteristics of different infrastructures.

Various similar climbing methods have recently been developed to inspect cylindrical or circular truncated cone structures. For example, Figure 2a shows, the development of a "ring" climbing robot with a payload capability allowing it to climb around the cylindrical tower. The prototype has three modules that are completely identical and can be easily joined together to climb on any circumferential tube. The wheels depend on spring forces to grip around and climb on the tower. The innovation of the robot is that its adhesive forces are provided entirely by springs rather than conventional adhesion methods (such as vacuum suction, magnetic force, and dry adhesions) [16]. Figure $2 b$ shows a robot with a cylindrical or conical shape. The robot utilizes a rolling self-locking concept: rolling allows continuous ascension whereas self-locking guarantees null energy consumption while staying still on the pole. However, the robot could only climb up a pole with a high coefficient of friction or else it will slip [17]. The development of a wheel-based pole climbing robot is shown in Figure 2c. It is designed for climbing stepped poles with circular or near-circular cross-sections [18] and consists of a triangular body and six limbs with ordinary wheels at their tips. Three lower wheels are actuated with DC motors. The upper limbs have passive wheels and act just to increase system stability [19]. Figure $2 \mathrm{~d}$ shows the design of a tree-climbing robot which has anti-falling functionality and can climb tree trunks of various diameters vertically or in a spiral pattern $[20,21]$. The RETOV robot Figure 2e can change its movement direction describing three different types of motion. Pure rotational and translational motion can be obtained independently when all three drive wheel systems are horizontally and vertically oriented, respectively (servomotor at $0^{\circ}$ and $90^{\circ}$ respectively). Pitch variable helical movements are also possible when the same acute orientation angle is defined for all the three-wheel systems [22]. A friction-based multi-robot approach is the climbing ring robot, see Figure $2 \mathrm{f}$-also known as Scanning, Monitoring, Analyzing, Repair, and Transportation (SMART)—can carry high payloads and is equipped with an onboard robotic arm. The SMART robot clasps the tower surface and climbs up and down with friction-based crawlers [23]. Table 1 shows the existing climbing robot considering the different methods in its locomotion, adhesion, structural design, application robot's weight and the diameter of the application of the climbing robot in pole, tower, tree and pipelines. After reviewing previous research about climbing robot and considering many factors such as cost, material and time constraints, a modular mechanism with a compact design has been proposed to be implemented in the robot design. The problem statement is to design a climbing robot that reduces mechanical complexity, fulfill the stability against breaking or slipping, carrying load capacity and using a new approach of adhesion for the winding mechanism. Lastly, wheeled locomotion is always faster than legged locomotion and the use of rubber could provide a strong grip while minimizing the damage of the wind turbine tower surface. 


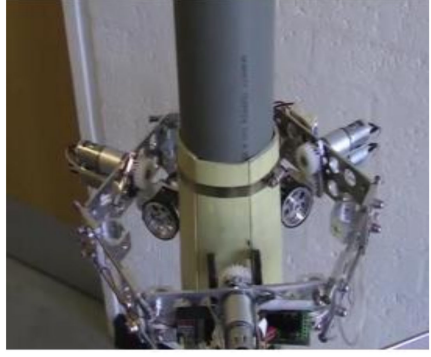

(a)

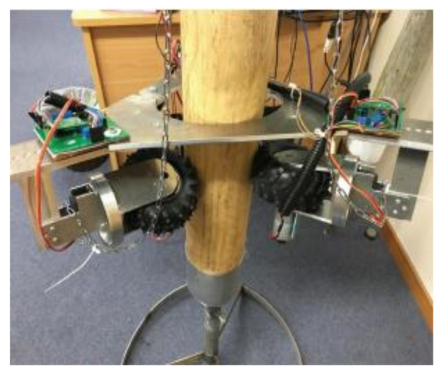

(d)

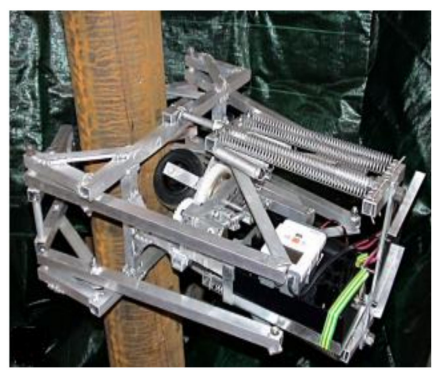

(b)

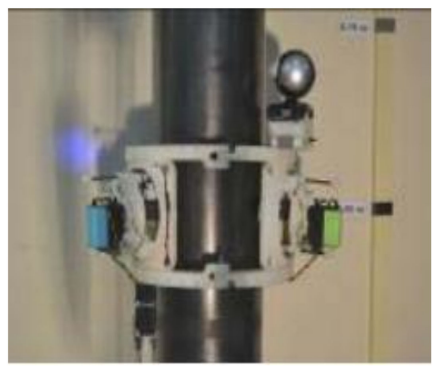

(e)

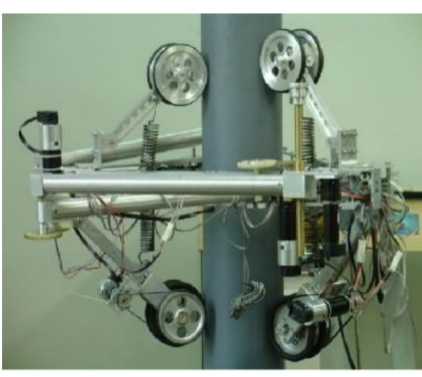

(c)

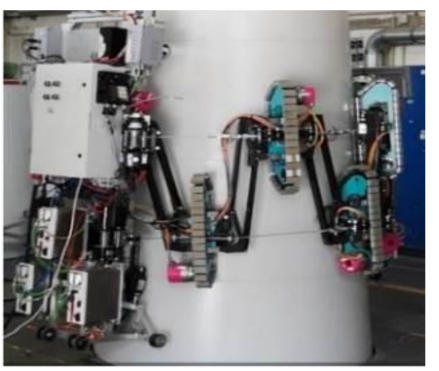

(f)

Figure 2. Design studies: (a) "Ring" climb robot [16]; (b) Pobot V2 [17]; (c) the UT-PCR) [18,19]; (d) Tree Pruning Robot [20,21]; (e) the RETOV [22]; and (f) Multi-Robot [23].

Table 1. Existing climbing robots.

\begin{tabular}{|c|c|c|c|c|c|c|}
\hline $\begin{array}{l}\text { Types of } \\
\text { Climbing } \\
\text { Robot }\end{array}$ & Locomotion & Adhesion & Structural Design & Application & Weight & $\begin{array}{c}\text { Diameter of the } \\
\text { Application (Pole, Tower, } \\
\text { Tree, Pipelines) }\end{array}$ \\
\hline $\begin{array}{l}\text { "Ring" Climb } \\
\text { Robot [16] }\end{array}$ & Wheel based & $\begin{array}{l}\text { Mechanical- } \\
\text { spring traction }\end{array}$ & $\begin{array}{l}\text { "Ring" robot in } \\
\text { trisection Y-type design }\end{array}$ & $\begin{array}{l}\text { Cylindrical } \\
\text { tower }\end{array}$ & $3 \mathrm{~kg}$ & $100 \mathrm{~mm}$ \\
\hline Pobot V2 [17] & Wheel based & $\begin{array}{l}\text { Mechanical-static } \\
\text { self-locking }\end{array}$ & $\begin{array}{l}\text { Rectangular body and } \\
\text { folded shape of arm }\end{array}$ & Conical pole & $10.5 \mathrm{~kg}$ & $300-100 \mathrm{~mm}$ \\
\hline $\begin{array}{c}\text { The UT-PCR } \\
{[18,19]}\end{array}$ & Wheel based & $\begin{array}{l}\text { Mechanical- } \\
\text { spring traction }\end{array}$ & $\begin{array}{l}\text { Triangular body and } \\
6 \text { limbs }\end{array}$ & Conical pole & $\mathrm{N} / \mathrm{A}$ & $80 \mathrm{~mm}$ \\
\hline $\begin{array}{l}\text { Tree Pruning } \\
\text { Robot }[20,21]\end{array}$ & Wheel based & $\begin{array}{l}\text { Mechanical—stepper } \\
\text { and screw nut unit }\end{array}$ & $\begin{array}{l}\text { Active and passive } \\
\text { Anti-falling platform } \\
\text { and } 3 \text { legs }\end{array}$ & Tree trunk & $5.32 \mathrm{~kg}$ & $100 \mathrm{~mm}$ \\
\hline $\begin{array}{l}\text { The RETOV } \\
\text { [22] }\end{array}$ & Wheel based & $\begin{array}{l}\text { Magnetic- } \\
\text { micro motors }\end{array}$ & $\begin{array}{l}\text { Two articulated rings } \\
\text { and } 3 \text { drive } \\
\text { wheel system }\end{array}$ & Pipelines & $1 \mathrm{~kg}$ & $220 \mathrm{~mm}$ \\
\hline $\begin{array}{l}\text { Multi-Robot } \\
\text { [23] }\end{array}$ & Track based & $\begin{array}{l}\text { Mechanical- } \\
\text { tension straps }\end{array}$ & $\begin{array}{c}\text { Tracked vehicle design } \\
\text { and tracked drive } \\
\text { chassis frame }\end{array}$ & $\begin{array}{l}\text { Wind } \\
\text { turbines }\end{array}$ & $400 \mathrm{~kg}$ & $3-4 \mathrm{~m}$ \\
\hline
\end{tabular}

This study proposed a climbing model which adapts for a scaled-down $2 \mathrm{MW}$ wind turbine tower. It is supported by a winding mechanism that utilizes a steel rope traction to optimize the force of the robot's driving wheel. The innovation of this climbing robot is that its method of adhesion uses a tension rope force to grip rather than conventional techniques such as magnetic adhesion, vacuum suction, electrostatic adhesion and propeller-type adhesion. The traction of the tension force needs to adapt the different diameter of the wind turbine tower, as it climbs through a circular truncated cone shape. The rope traction ensures a high degree of safety in the inspection and maintenance of the wind turbine, either onshore or offshore. The locomotion mechanism is a wheel-based mode for a faster and more robust climb. The four rubber wheels in contact with the wind turbine tower will provide sufficient friction as they roll on the tower surface and are prevented from slipping. This climbing robot can facilitate movement in a straight up-down motion with the wired 
DC power supply. Concerning the robot carrying load capability, it should be optimized to be strong and safe enough for carrying inspection or maintenance tools. With these goals, the approximate carrying payload is estimated at least $50 \%$ from the robot total weight against breaking or slipping. The mechanical design was analyzed and calculated as the most significant aspect, and the controller architecture of the climbing robot and the new approach of adhesion are shown in Section 2. It has been successfully tested to prove the stability of the innovative climbing design and experiment results are detailed in Section 3, and finally a conclusion is presented in Section 4 .

\section{Materials and Methods}

The materials and methods involved in the study highlight the design that consists of the robot model, force analysis, the robot controller architecture, winding mechanism and the evaluation of the development of a climbing robot for wind turbine maintenance. Baseline research is conducted in an effort to benchmark relevant studies.

\subsection{Climbing Robot Model Design}

The overall mechanical design of the wind turbine climbing robot is shown in Figure 3. The design consists of three parts: the driving mechanism, winding mechanism, and body frame. The embedded microprocessor and other electronics accessories are attached to the body frame. The driving mechanism is adopted for obtaining maximum climbing speeds and includes the mechanism for up-down motion. The robot utilizes four DC motors to climb on the circular truncated cone tower being power supplied by a $12 \mathrm{~V}$ DC power. The DC motors provide high torque and high power to drive the robot up and down motion along the tower surface. The body frame is made of two parts to have a lightweight structure, ease of installation and transport. It supports all the driving wheels and holds the winding mechanism with the two stepper motors and steel rope. The main functions of a stepper motor are to wind and unwind the steel rope within its ideal traction force. Once the climbing robot is set up on the tapered wind turbine tower, the frame is locked and uses a tension force to grip it. This special winding mechanism maintains a safe distance of the robot to the tower diameter surface. The stepper motor together with the steel rope is a primary mechanism that adjusts the different diameter of the circular truncated cone tower to grip on the surface without falling to the ground. With this design, the robot has the potential to adapt to the tapering tower diameter structures and provide mobility capabilities to examine the circumference of the tower.

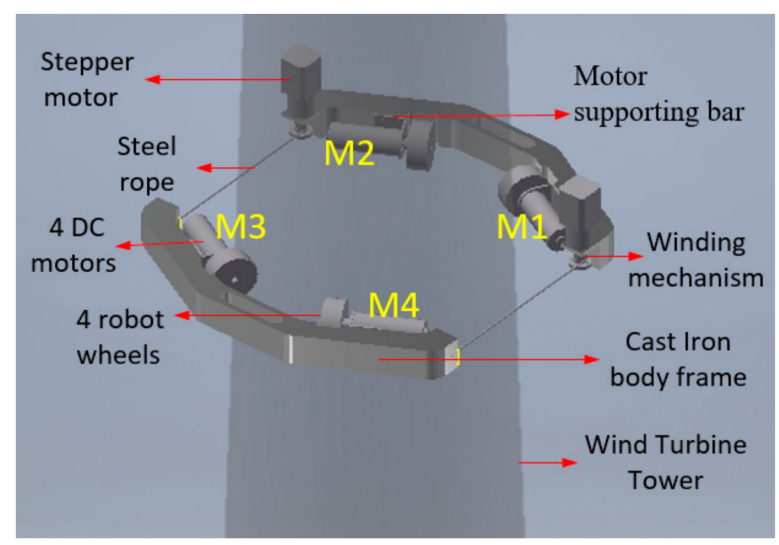

Figure 3. Wind turbine climbing robot model.

The entire system of climbing robot is made up of two body frames that have a winding mechanism, dimensions as reckoned with both side views and top views are shown in Figure 4. The robot has two body frames with a height of $45 \mathrm{~mm}$ as shown in Figure $4 \mathrm{a}$, a length of $500 \mathrm{~mm}$ as shown in Figure $4 \mathrm{~b}$, and each body frame weighs $2 \mathrm{~kg}$. It is made of aluminum alloy 6061 material which is lightweight and economical. Figure $4 \mathrm{~b}$ 
shows the robot rubber wheels in contact with the wind turbine tower with the distance of $427.44 \mathrm{~mm}$ from M1 to M3 and from M2 to M4, which will constantly change as the robot moves along the tower surface. The tapering wind turbine tower is made of steel material with an average base diameter of $400 \mathrm{~mm}$ and the top diameter is $330 \mathrm{~mm}$. If the robot is at the lower segment of the tower, the diameter distance is increased and as it moves upward, the diameter distance decreases. This change in diameter leads to a variation in length and forces. The electronic control circuit and the distance sensor attain the ideal traction force of the robot to move up-down the tower. The mechanical design is carried out with the aid of 3D modeling software Autodesk Inventor. The force analysis was performed to check the capabilities of the robot to climb in a circular truncated cone tower and holding onto the tower surface at a gradient angle. The robot weight, wheel torque, traction force, and the coefficient of friction between the wheel tires and tower surface were taken into consideration. It is important to determine the inclination angle and the wheel torque at an equilibrium state where the robot moves with constant speed to attain the synchronization of body frame as it climbs the tower. Then, all forces, the inclination angle and the torques can be managed to meet the climbing scenarios needed.

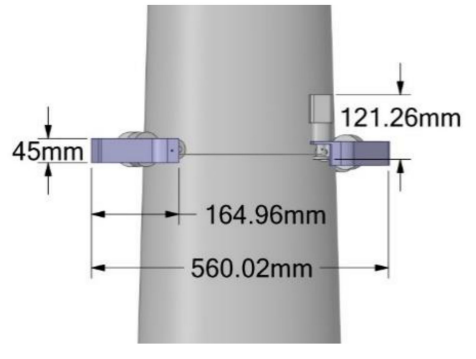

(a)

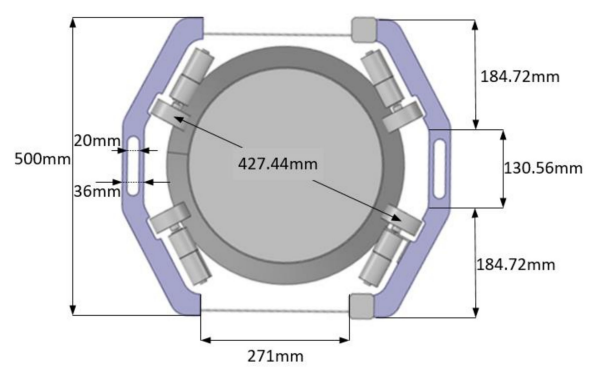

(b)

Figure 4. Climbing robot dimensions: (a) side view; and (b) top view.

\subsection{Force Analysis}

A force analysis model was crafted to determine the adhering forces needed in the wind turbine climbing robot and the moments applied in the robot under the static condition. And the robot wheel is assumed to make contact with the tower surface by the gravitational force without consuming energy as illustrated in Figure 5.

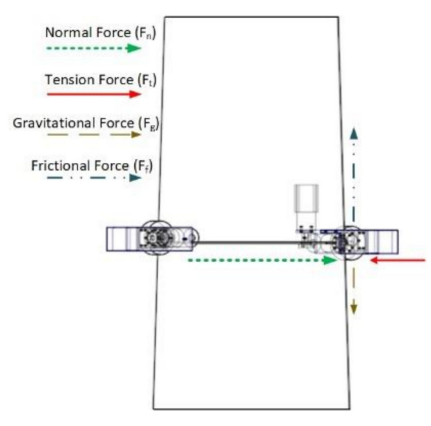

(a)

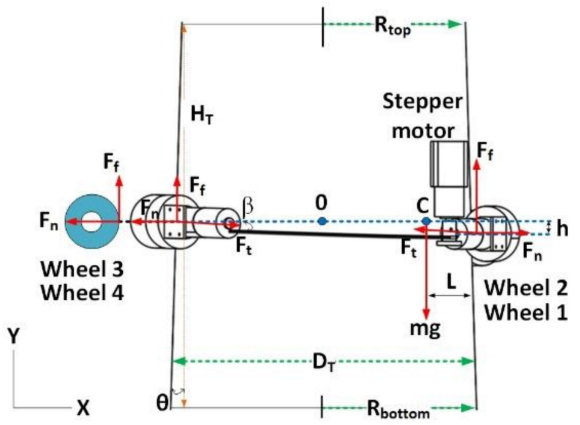

(b)

Figure 5. (a) Forces of the climbing robot; and (b) forces in lateral view.

Figure 5 a shows that the forces of the climbing robot are the normal force $\left(F_{n}\right)$, which is the support force on the wheels and perpendicular to the contact surface; the tension force $\left(\mathrm{F}_{\mathrm{t}}\right)$, which is the force from the steel rope to attain the ideal traction force; the gravitational force $\left(\mathrm{F}_{\mathrm{g}}\right)$, which is the gravitational force of the robot; and the frictional force $\left(\mathrm{F}_{\mathrm{f}}\right)$, which is the force between the rubber wheels and the tower surface. These are the necessary forces for the climbing robot to adhere on the tower surface. Figure $5 \mathrm{~b}$ illustrate the lateral view 
of the robot force analysis. It also assumes that there is no slip with respect to the circular truncated cone tower. Practically, no robot can keep a perfect horizontal position because of structure deformation [17]. Because there are two stepper motors installed in one of its body frames in the robot, this will cause the uneven distribution of robot mass that leads to the robot center of mass not coinciding with the other body frame structure. Thus, the climbing robot can hang itself on the tower under static conditions without consuming any energy and resist free falling to the ground. Equations (1) and (2) come from the resultant forces in the $y$ direction under the equilibrium state of the forces applied to the robot based on Coulomb's force of friction, where the normal forces provide the frictional force by multiplying the friction coefficient together with the inclination angle. Equation (3) shows the inclination angle of the tapered tower covered by the robot in the circular truncated cone shape:

$$
\begin{gathered}
\sum \mathrm{F}_{y}=0 \\
\sum \mathrm{F}_{y}=\left(\mathrm{F}_{n 1} \mu\right) \cos \theta+\left(\mathrm{F}_{n 2} \mu\right) \cos \theta+\left(\mathrm{F}_{n 3} \mu\right) \cos \theta+\left(\mathrm{F}_{n 4} \mu\right) \cos \theta=\mathrm{mg} \\
\sum \mathrm{F}_{y}=\mu \cos \theta\left(\mathrm{F}_{n 1}+\mathrm{F}_{n 2}+\mathrm{F}_{n 3}+\mathrm{F}_{n 4}\right)=\mathrm{F}_{\mathrm{g}} \\
\theta=\arctan \left\{\left(\mathrm{R}_{\text {bottom }}-\mathrm{R}_{\mathrm{top}}\right) / \mathrm{H}_{\mathrm{T}}\right\}
\end{gathered}
$$

where $\mathrm{F}_{y}$ and $\mathrm{F}_{x}$ are the resultant vertical and horizontal projection forces; $\mathrm{F}_{n 1}, \mathrm{~F}_{n 2}, \mathrm{~F}_{n 3}$ and $\mathrm{F}_{n 4}$ are the normal forces applied on the four wheels at the contact points between the rubber and steel tower, $\mu$ is the static friction coefficients, $\mathrm{m}$ represents the mass of the robot, $\mathrm{g}$ the acceleration of gravity, $\mathrm{F}_{\mathrm{g}}$ being the mass of the robot and gravitational acceleration, $\theta$ is the inclination angle of the tower, $\mathrm{H}_{\mathrm{T}}$ is the height of the tower, $r$ is the radius of the robot wheel, $D_{T}$ is the diameter of the tapered wind turbine tower, $R$ is the radius of the tapered wind turbine tower, $R_{\text {bottom }}$ is the bottom tower radius, $R_{\text {top }}$ is the top tower radius, $\beta$ is the angle of the tension force between the robot's body frame, $\mathrm{L}$ is the length from the surface of the tower to the robot center mass, $\mathrm{O}$ is the center of origin, $C$ is the center of mass, and $h$ is the height difference of wheels 1 and 2 to wheels 3 and 4 due to the weight of the body frame and DC motors:

$$
\begin{gathered}
\sum \mathrm{F}_{x}=0 \\
\sum \mathrm{F}_{x}=\mathrm{F}_{n 1} \cos 28^{\circ}+\mathrm{F}_{n 2} \cos 28^{\circ}-\mathrm{F}_{n 3} \cos 28^{\circ}-\mathrm{F}_{n 4} \cos 28^{\circ}+\mathrm{F}_{f 1} \cos 62^{\circ} \\
+\mathrm{F}_{f 2} \cos 62^{\circ}-\mathrm{F}_{f 3} \cos 62^{\circ}-\mathrm{F}_{f 4} \cos 62^{\circ}+2 \mathrm{~F}_{\mathrm{t}}
\end{gathered}
$$

As a result of the forces in the $x$-direction, tension force gives Equation (4), assuming that when the robot can hang itself on the tower, wheels 1 and 2 equate to wheels 3 and 4 with the desired wheel angle of the robot and the tension force from the two stepper motors that alter the distance between the tower center and the center of the robot wheel. This also gives equilibrium moments and contact points on the four robot wheels as shown Figure 6.

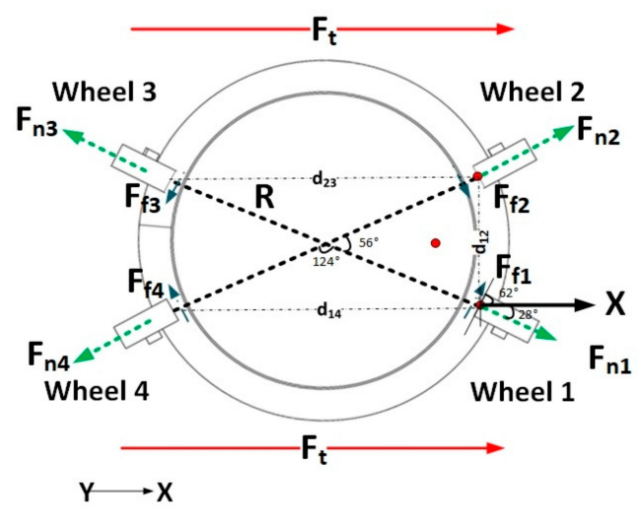

Figure 6. Force and moment in top view 
Under equilibrium conditions, assuming wheels 3 and 4 stay at the same level, which is higher than the position of wheels 1 and 2, then the moment arm from the pivot point of wheel 1 is defined as

$$
\begin{aligned}
& d_{14}=d_{23}=\sqrt{ } R^{2}+R^{2}-\left(2 R^{2} \cos 124^{\circ}\right) \\
& d_{12}=d_{21}=\sqrt{ } R^{2}+R^{2}-\left(2 R^{2} \cos 56^{\circ}\right)
\end{aligned}
$$

and the equilibrium of the moment at the lower wheel's (wheel 1) contact point gives:

$$
\sum \mathrm{M}=0
$$

The pivot point at wheel 1 with different wheel height:

$$
\begin{gathered}
\curvearrowleft \sum \mathrm{M}=\mathrm{mgL}+\left(\mathrm{F}_{n 3} \cos 28^{\circ}\right) \mathrm{h}_{3}+\left(\mathrm{F}_{n 4} \cos 28^{\circ}\right) \mathrm{h}_{4}+\left(\mathrm{F}_{n 2} \cos 28^{\circ}\right) \mathrm{h}_{2}-\left(\mathrm{F}_{n 3} \mu\right) 2 \mathrm{R}- \\
\left(\mathrm{F}_{n 4} \mu\right) \mathrm{d}_{14}+\left(\mathrm{F}_{n 2} \mu\right) \mathrm{d}_{12}-\left(\mathrm{F}_{t 1} \cos \beta_{1}\right) \mathrm{h}_{4}-\left(\mathrm{F}_{t 2} \cos \beta_{2}\right) \mathrm{h}_{3}=0
\end{gathered}
$$

The pivot point at wheel 2 with different wheel height:

$$
\begin{gathered}
\square \sum \mathrm{M}=\mathrm{mgL}+\left(\mathrm{F}_{n 3} \cos 28^{\circ}\right) \mathrm{h}_{3}+\left(\mathrm{F}_{n 4} \cos 28^{\circ}\right) \mathrm{h}_{4}+\left(\mathrm{F}_{n 1} \cos 28^{\circ}\right) \mathrm{h}_{1}-\left(\mathrm{F}_{n 4} \mu\right) 2 \mathrm{R}- \\
\left(\mathrm{F}_{n 3} \mu\right) \mathrm{d}_{23}+\left(\mathrm{F}_{n 1} \mu\right) \mathrm{d}_{12}-\left(\mathrm{F}_{t 1} \cos \beta_{1}\right) \mathrm{h}_{4}-\left(\mathrm{F}_{t 2} \cos \beta_{2}\right) \mathrm{h}_{3}=0
\end{gathered}
$$

where $\mathrm{h}_{1}, \mathrm{~h}_{2}, \mathrm{~h}_{3}$, and $\mathrm{h}_{4}$ are the height differences of each wheel from the pivot points, and $\beta_{1}$ and $\beta_{2}$ are the angles of the tension force between the robot's body frame in reference to the $x$ axis.

Equations (5) and (6) show the moment around the center of gravity of the robot. This indicates that to keep the robot on the tower, the robot wheels should have sufficient friction to support the weight of the robot and high enough tension force to the tower to hold in a vertical position.

As the robot climbs upwards, forces and moments are generated by rolling tire deformation and the DC motor's torque should overcome the force of rolling resistance, robot gravity, and acceleration resistance. The rolling resistance is an energy dissipation process to overcome the resistive force and thus drive the tire forward [24]:

$$
\mathrm{F}_{\mathrm{r}}=\left(\mathrm{F}_{\mathrm{n}} \mathrm{b} / r\right)
$$

$\mathrm{F}_{\mathrm{r}}$ is the rolling resistance force, $\mathrm{F}_{\mathrm{n}}$ the normal force, $\mathrm{b}$ coefficient of rolling friction, $r$ is the radius of the robot wheel. The weight of the robot is one of the primary considerations in climbing robot design since it directly affects the value of the robot gravitational force. Under various conditions, this force of gravity can accelerate or decelerate the speed of the robot and the mechanical operation of the mechanism. The four DC motors need to overcome the inertia force $\mathrm{F}_{\mathrm{i}}$ caused by the robot mass during the accelerated movement. In general, the inertia force causes the lift force that is in opposite in direction to an accelerating force acting on a body, as shown in Figure 7.

$$
\mathrm{F}_{\mathrm{i}}=\mathrm{m}(d v / d t)
$$

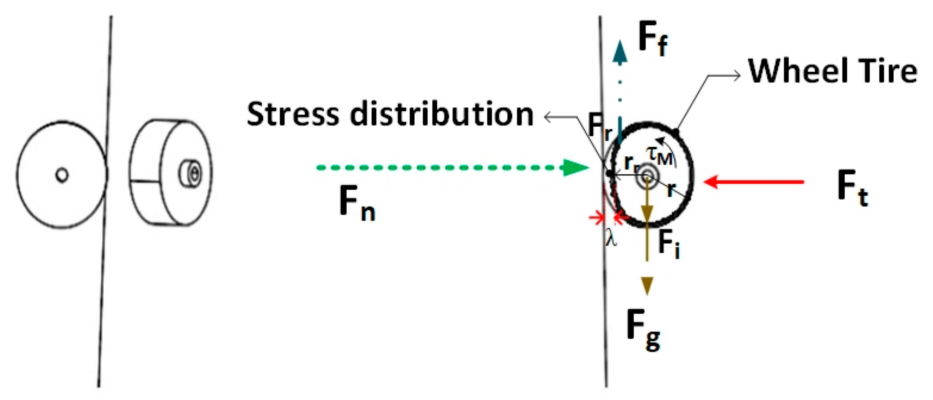

Figure 7. Force and torque analysis. 
The inertia torque caused by the acceleration resistance is:

$$
\begin{gathered}
\tau_{\mathrm{i}}=\mathrm{I} \alpha \\
\tau_{\mathrm{i}}=\mathrm{F}_{\mathrm{i}} r_{r}
\end{gathered}
$$

where I is the wheel rotational inertia, $\alpha$ is the wheel angular acceleration, and $r_{r}$ is the wheel rolling radius:

$$
\begin{gathered}
\mathrm{F}_{\mathrm{m}}=\mathrm{F}_{\mathrm{r}}+\mathrm{F}_{\mathrm{g}}+\mathrm{F}_{\mathrm{i}} \\
\tau_{\mathrm{m}}=\tau_{\mathrm{r}}+\tau_{\mathrm{g}}+\tau_{\mathrm{i}} \\
\tau_{\mathrm{m}}=\tau_{\mathrm{r}}(\lambda)+\tau_{\mathrm{g}}\left(r_{r}\right)+\tau_{\mathrm{i}}\left(r_{r}\right) \\
\mathrm{F}_{\mathrm{t}}=\alpha \mathrm{F}_{1}
\end{gathered}
$$

$F_{m}$ and $\tau_{m}$ are the force and torque required for the DC motor, respectively. $\tau_{r}$ is the rolling resistance torque; $\tau_{\mathrm{g}}$ is the robot gravity torque; and $\lambda$ is the vertical offset distance of the resultant normal force due to the tire deformation. $\mathrm{F}_{\mathrm{t}}$ keeps the robot from falling with the desired tension force that is equal to the force tension factor $(\gamma)$ and the load force $F_{1}$. The stress $(\sigma)$ on the rubber tire deformation obtained by tension force to grip on the tower surface that equates normal force acting perpendicular to the (A) area can be determined to be as

$$
\sigma=\mathrm{Fn} / \mathrm{A}
$$

In other words, forces and moments exerted by the climbing robot all around the tower can cause stress that also depends on the modulus of elasticity (E) of the rubber. Thus, the strain $(\varepsilon)$ can be calculated as

$$
\varepsilon=\sigma / \mathrm{E}
$$

\subsection{Wind Turbine Tower Model Assumption}

A scaled-down wind turbine tower model has been adopted from a real $2 \mathrm{MW}$ wind

\begin{tabular}{|c|c|c|c|c|}
\hline \multicolumn{5}{|c|}{$\begin{array}{c}\text { Turbine Description: 2.0 MW Turbine from Vestas V80. } \\
\text { Tower Material: Steel }\end{array}$} \\
\hline & & $\mathrm{D}_{\text {top }}(\mathrm{mm})$ & $\mathrm{D}_{\text {bottom }}(\mathrm{mm})$ & Tower Height (mm) \\
\hline \multirow{3}{*}{ Original Tower Dimension } & Top Section & 2314 & 2822 & 28,990 \\
\hline & Middle Section & 2822 & 3488 & 29,005 \\
\hline & Third Section & 3488 & 4186 & 17,660 \\
\hline \multicolumn{2}{|c|}{ Scaled-Down Tower } & 330 & 400 & 1200 \\
\hline \multicolumn{2}{|c|}{ Inclination Angle } & & $1.67^{\circ}$ & \\
\hline
\end{tabular}
turbine which has a height around $78 \mathrm{~m}$. As shown in Table 2, a modern wind turbine tower is usually assembled by 3 steel sections with tower dimensions of $4186 \mathrm{~mm}$ at the bottom and $2314 \mathrm{~mm}$ at the top. To simulate the climbing robot design, a tapered wind turbine mock-up was created with predefined tower dimensions of $330 \sim 400 \mathrm{~mm}$ for the tower diameters, $1200 \mathrm{~mm}$ for the tower height and a $1.67^{\circ}$ inclination angle for a simplified testing scenario.

Table 2. Tower dimension assumption for the climbing robot and force analysis.

\subsection{Controller Architecture}

The control of the climbing robot is realized as shown in Figure 8. The embedded microprocessor is the Arduino MEGA 2560, which integrates all the controls of the updown movement, winding mechanism and distance sensor in the entire system. This microcontroller was chosen for its small size, low cost and reliability to control the six 
motors of the climbing robot. It is more than enough for the development of the robot as it requires a simple control process and a minimal programing code. The power supply of the proposed system is a $12 \mathrm{~V}$ DC source. It is directly supplied to the DC motors and the regulated $5 \mathrm{~V}$ voltage source is used to power up the embedded microprocessor and other board. The robot utilizes four independently motorized wheels and the GP-BLDC3650 as the locomotion of the robot to push the whole mechanism upward and downward. The DC motor was chosen as it provides sufficient torque rated at $8 \mathrm{~kg} . \mathrm{cm} / 0.78 \mathrm{Nm}$ and the power to overcome the resistance force while having an adequate speed rotation rated at 70-150 rpm. The four independent DC motors/encoders have high torque and high self-retaining power to drive the mechanism and enable it to climb on the circular truncated cone tower. The four onboard wheels are coated with rubber to maintain high surface friction and prevent slipping. The winding mechanism uses two stepper motors that control the steel rope tension force in winding and unwinding to achieve the optimum traction between the two-body frame in the tower. The winding mechanism utilizes a series hybrid stepper motors-42HS03 that has a holding torque of $0.47 \mathrm{~nm}$ and a detent torque of $0.204 \mathrm{~kg} . \mathrm{cm} / 0.020 \mathrm{Nm}$. Thus, it provides flexibility in changing the diameter and providing adequate tension force to the grip around the tower for robot mobility. Along the CNC (Computer Numeric Control) shield and encoder are also connected between the microcontroller and the motor to protect any current surge from the supply. The distance sensor which utilizes TOF10120 maintains an equilibrium distance between the two-body frame of the robot to the tower surface. As the climbing robot moves up and down, the sensor gives feedback signals to the embedded microprocessor module to attain the proper traction in the tower circumference and to prevent slipping.

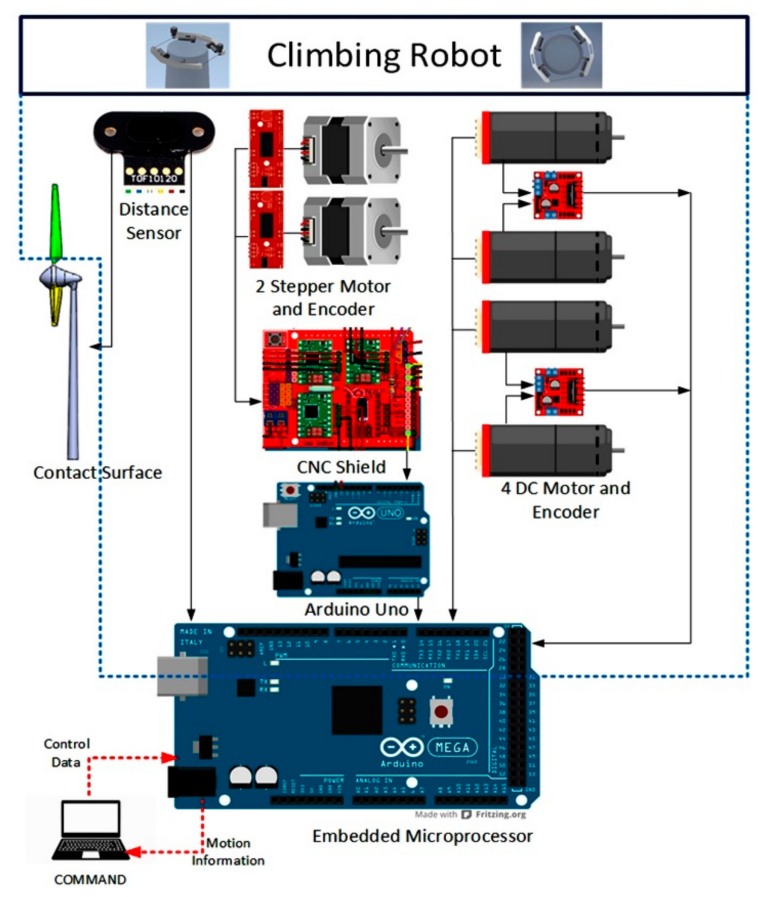

Figure 8. Controller architecture of the climbing robot.

\subsection{Winding Mechanism}

This special winding mechanism maintains a safe distance between the robot and the tower diameter surface. As shown in Figure 9, during the process of the robot climbing, the distance sensor can determine the length from the other side of the robot body frame if the distance is too close or far. Thus, the process is executed by the stepper motor and the steel rope to wind and unwind. The embedded microprocessors give a prompt to the stepper motor to wind or unwind the steel rope, based on the signal of the distance sensor. If the 
correct distance is attained, it stops the winding or unwinding process, then remeasures the distance. If the correct distance is not attained, it continues to measure the distance.

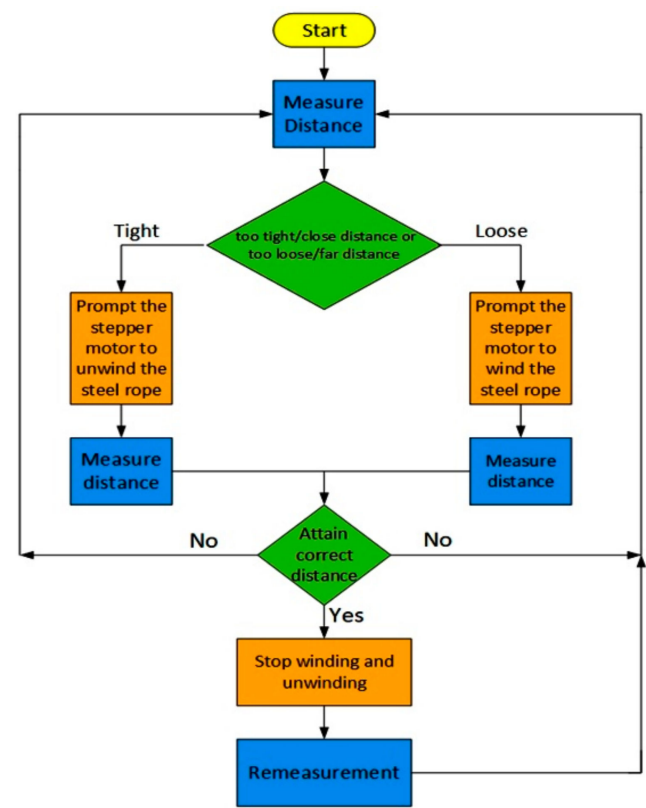

Figure 9. Winding mechanism flowchart.

\section{Results and Discussions}

The scaled-down climbing robot design verification was tested in an indoor experimental setting. The first prototype testing was conducted to evaluate the performance of the winding mechanism and its locomotion. Figure 10 shows the winding mechanism that is prompt from the distance sensor to attain the proper tension force to ensure good traction for climbing. Once the precision measured on the four rubber wheels is obtained, the robot started its mobility to go up straight on the tower. The robot requires $3 \mathrm{~s}$ to cover the upward mobility of the tapered tower height of $1200 \mathrm{~mm}$ and the tower diameter for climbing 330 400 $\mathrm{mm}$. The robot has dimensions of $500 \mathrm{~mm} \times 164.96 \mathrm{~mm} \times 45 \mathrm{~mm}$ for each body frame, with an average weight of $2 \mathrm{~kg}$ per body frame.

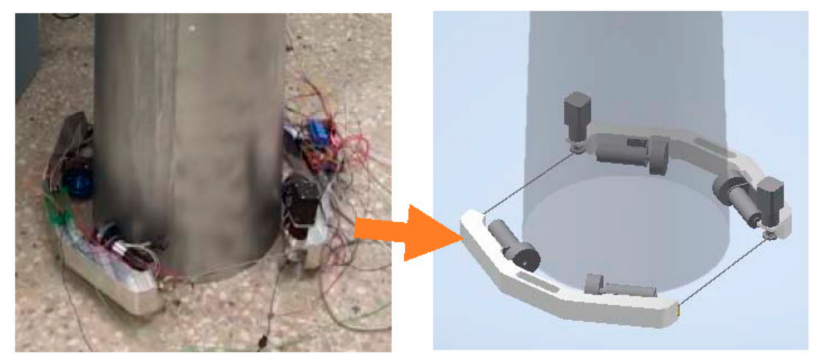

Figure 10. Climbing robot at the bottom part of wind turbine tower.

Figure 11 shows the climbing process of the robot in a circular truncated cone tower. This reveals that the robot traction force from the winding mechanism has to be greater than the robot gravity force in climbing along the tower surface with an average speed of $120 \mathrm{~mm} / \mathrm{s}$, which shows a good performance of the tapering tower diameter structures of a wind turbine. The sufficient traction force coming from the steel rope and stepper motors demonstrated its absolute necessity to create friction on the robot wheels as it climbs. The robot may ascend and halt along the tower surface and continue ascending in the tower without slipping. As the robot descends along the tower, it also generates a strong traction force from the winding mechanism and requires a contact pressure decrease as the stepper motor unwinds the steel rope. The adaptability of the different diameter 
of the wind turbine tower, as it climbs through a circular truncated cone shape, caused no problem.

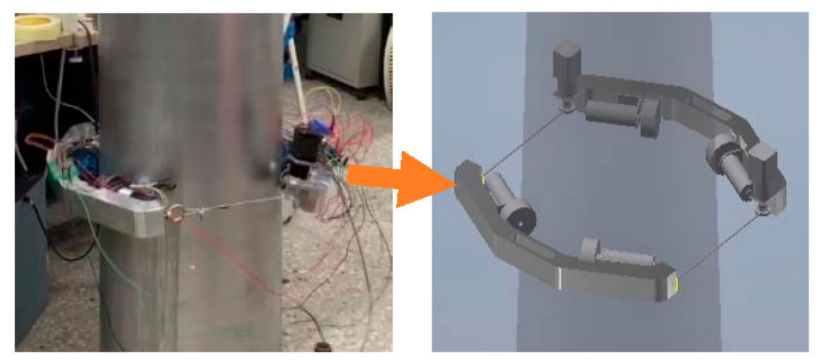

Figure 11. Climbing robot in the middle part of wind turbine tower.

Figure 12 shows that the robot weight is $8.2 \mathrm{~kg}$ and includes the entire electronics assembly module and electric wires and maximum payload capacity of $4.4 \mathrm{~kg}$ with a safe factor of two. The result shows that the climbing robot can withstand the different load on the robot body frame without consuming power. The stability against breaking or slipping from the torque of the winding mechanism is sufficient for the robot to perform the climbing process in a circular truncated cone tower.

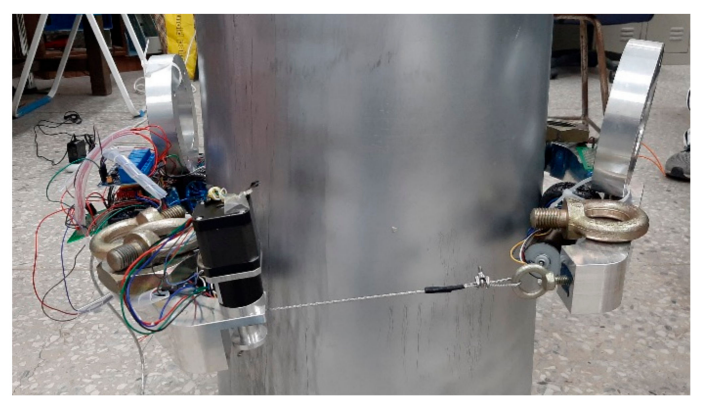

Figure 12. Climbing robot payload capacity.

The experiment testing results show that the prototype design of the climbing robot can perform its winding mechanism and locomotion along the tower with $1.67^{\circ}$ inclination angle, as shown in Figure 13. The test allowed to exhibit the limit state of climbing a tower that the robot needs to provide an ideal force of traction to support all the weight of the climbing robot. The critical point is the equilibrium weight of each body frame that needs to be compensated for the equal distribution of force but in totality the scaled-down prototype climbs successfully on the tapered tower.

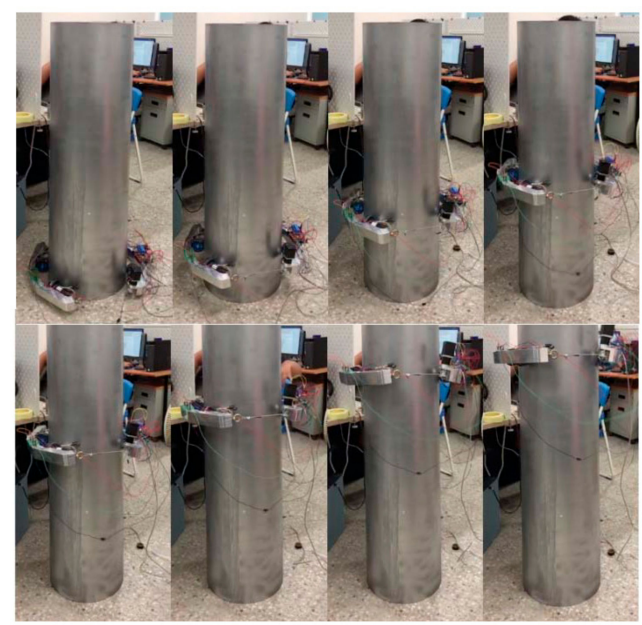

Figure 13. Wind turbine climbing robot physical test model. 
Table 3 shows the specifications of the climbing robot while Table 4 shows the specification of the DC motor for its locomotion and stepper motor for the winding mechanism. Figure 14 shows the current swing of the four DC motors with and without load. The value of the current during the climbing process was measured to be within a $1.4 \mathrm{~A}$ range. As the robot has a load, the DC motor current shows an erratic swing due to the several factors needed in the climbing process. The data are generated during the preliminary climbing scenario test run as shown in Figure 15: it climbs $1150 \mathrm{~mm}(1.1 \mathrm{~m})$ up in around $10 \mathrm{~s}$. The average speed of the robot to go up and down is $120 \mathrm{~mm} / \mathrm{s}$ with the wheel radius of $32.5 \mathrm{~mm}$. The constant tension force applied by the steel rope and the stepper motor to the variable diameter tower to keep the robot in contact is 81.9 N. Figure 16 displays the increased force or tension in a rope due to angle $\gamma$ and the force tension factor.

Table 3. Climbing robot specification.

\begin{tabular}{|c|c|c|c|}
\hline \multicolumn{2}{|l|}{ Parameters } & \multicolumn{2}{|c|}{ Actual Values } \\
\hline \multirow{2}{*}{ Robot weight } & Body frame weight & \multirow{2}{*}{$8.2 \mathrm{~kg}$} & $2 \mathrm{~kg} \times 2=4 \mathrm{~kg}$ \\
\hline & Motors, electronic modules & & $4.2 \mathrm{~kg}$ \\
\hline \multicolumn{2}{|c|}{ Max payload weight } & \multicolumn{2}{|l|}{$4.4 \mathrm{~kg}$} \\
\hline \multicolumn{2}{|l|}{ Average speed } & \multicolumn{2}{|l|}{$120 \mathrm{~mm} / \mathrm{s}$} \\
\hline \multicolumn{2}{|l|}{ Current } & \multicolumn{2}{|l|}{$1.4 \mathrm{~A}$} \\
\hline \multicolumn{2}{|c|}{ Torque of the climbing robot } & \multicolumn{2}{|l|}{$0.78 \mathrm{Nm}$} \\
\hline \multicolumn{2}{|c|}{ Tension force of the rope } & \multicolumn{2}{|l|}{$81.9 \mathrm{~N}$} \\
\hline
\end{tabular}

Table 4. DC motor and stepper motor specification.

\begin{tabular}{lll}
\hline & DC Motor $\mathbf{- 1 2}$ V/24 V GP-BLDC3650 & Series Hybrid Stepper Motors-42HS03 \\
\hline Shaft length: & $20 \mathrm{~mm}$ & $48 \mathrm{~mm}$ \\
\hline Shaft diameter: & $8 \mathrm{~mm}$ D-shaped shaft & - \\
\hline Voltage: & $12 \mathrm{~V}$ & $12 \mathrm{~V}$ \\
\hline Current: & $1.8 \mathrm{~A}$ & $1.4 \mathrm{~A}$ \\
\hline Weight: & $445 \mathrm{~g}$ & $350 \mathrm{~g}$ \\
\hline Torque: & $1.5 \mathrm{~kg} \cdot \mathrm{cm}$ & $0.204 \mathrm{~kg} \cdot \mathrm{cm}$ \\
\hline Working speed & $70-150 \mathrm{rpm}$ & - \\
\hline Holding Torque & - & $0.47 \mathrm{Nm}$ \\
\hline Detent torque & - & $0.204 \mathrm{~kg} \cdot \mathrm{cm} / 0.020 \mathrm{Nm}$ \\
\hline
\end{tabular}

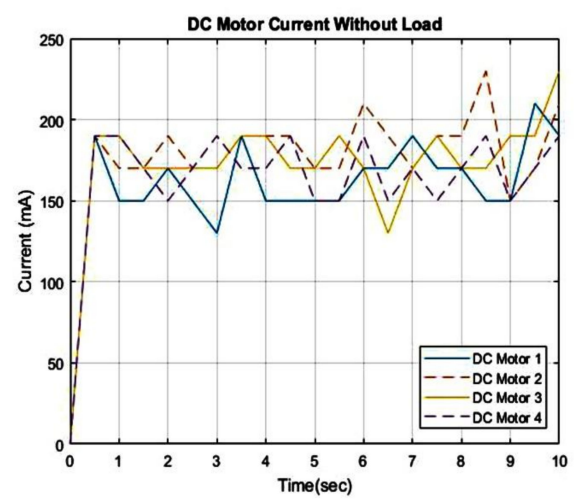

(a)

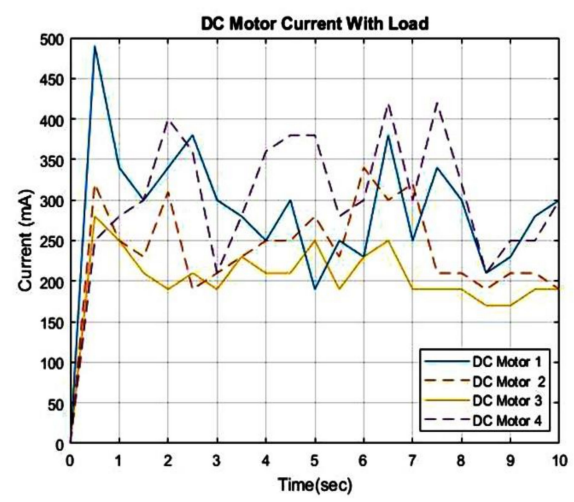

(b)

Figure 14. DC motor current: (a) without load; (b) with load. 


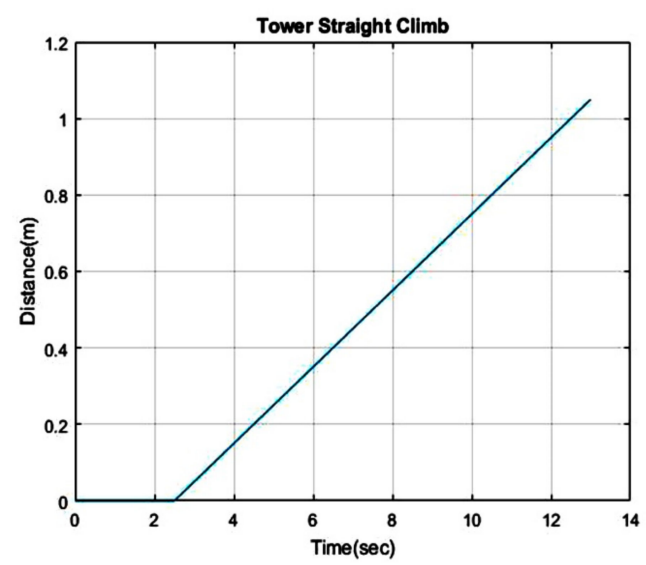

Figure 15. Straight climb.

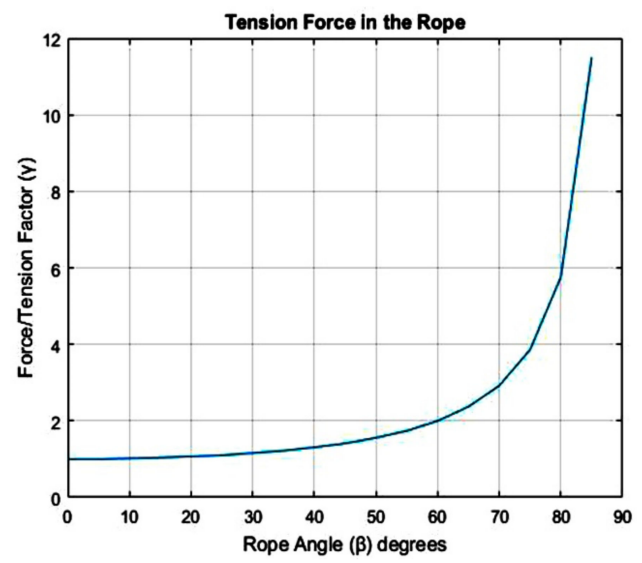

Figure 16. Tension force in the rope.

\section{Conclusions}

In this paper, the design and development of a wind turbine climbing robot have been presented and successfully tested the preliminary experiment of scaled-down prototype proving the functionality of the concept. The robot can climb in a straight up-down motion based on a new approach of adhesion the winding mechanism provided by the tension rope and rubber wheels as its locomotion. The scaled-down prototype has demonstrated that the climbing robot has the potential to taper the diameter of the wind turbine tower as it climbs. The carrying load capability to bear inspection tools should scale up to be able to meet the target capacity. The significant advantage of the design was the winding mechanism that can withstand the needed force to contract on the tower surface. The challenge in the study is to cope with a suitable material for rubber wheels so that the robot can diminish any deformities. The performance of the climbing robot prototype was demonstrated by the experimental results recorded in the video. The next step of this project was to optimize the wheels to further increase robot stability in terms of locomotion and transition like rotational and spiral motion. The prototype needs to be further improved and tested, especially for operation in different weather conditions. A future version of the climbing robot can be made to carry various equipment that are required for maintenance like the using sensors, camera for observation, a special robot arm for carrying inspection tools, etc. and increase the capability of the carrying load. The scale-up prototype is also considered for the maintenance and inspection tasks of a real wind turbine.

Author Contributions: Conceptualization: J.-H.L.; Data collection: K.P.; Theoretical analysis: J.-H.L. and Padrigalan, K.; Experiment and Test: J.-H.L. and K.P.; Writing-original draft: J.-H.L. and K.P.; Writing-review and editing: J.-H.L. and K.P. All authors have read and agreed to the published version of the manuscript. 
Funding: This research was supported by Astek Applied company and Industry Technology Research Institute (ITRI).

Institutional Review Board Statement: Not applicable.

Informed Consent Statement: Not applicable.

Data Availability Statement: Data sharing not applicable.

Conflicts of Interest: The authors declare no conflict of interest.

\section{References}

1. Rehfeld, K.; Wallasch, A.; Luers, S. Cost Situation of Onshore Wind Energy in Germany. Report by German Windguard. 2015. Available online: https:/ / www.windguard.de/veroeffentlichungen.html (accessed on 13 May 2020).

2. Tavakoli, M.; Viegas, C.; Marques, L.; Pires, J.N.; de Almeida, A.T. Omniclimbers: Omni-directional magnetic wheeled climbing robots for inspection of ferromagnetic structures. Robot. Auton. Syst. 2013, 61, 997-1007.

3. Alkalla, M.G.; Fanni, M.A.; Mohamed, A.F.; Hashimoto, S. Tele-operated propeller-type climbing robot for inspection of petrochemical vessels. Ind. Robot: Int. J. 2017, 44, 166-177.

4. Zhang, H.X.; Zhang, J.W.; Zong, G.H.; Wang, W.; Liu, R. Sky Cleaner 3: A real pneumatic climbing robot for glass-wall cleaning. IEEE Mag. Robot. Autom. 2006, 13, 32-41.

5. Wang, W.; Wang, K.; Zong, G.H.; Li, D.Z. Principle and experiment of vibrating suction method for wall-climbing robot. Vacuum 2010, 85, 107-112.

6. Koo, I.M.; Tran, D.T.; Lee, Y.H.; Moon, H.; Song, Y.K.; Choi, H.R. Development of Wall Climbing Robot System by Using Impeller TypeAdhesion Mechanism. J. Intell. Robot. Syst. 2013, 72, 57-72.

7. Asbeck, A.T.; Cutkosky, M.R. Designing compliant spine mechanisms for climbing. J. Mech. Robot. $2012,4,031007$.

8. Guan, Y.; Zhu, H.; Wu, W.; Zhou, X.; Jiang, L.; Cai, C.; Zhang, L.; Zhang, H. A modular biped wall-climbing robot with high mobility and manipulating function. IEEE/ASME Trans. Mechatron. 2013, 18, 1787-1798.

9. Lam, T.L.; Xu, Y. Climbing strategy for a flexible tree climbing robot-treebot. IEEE Trans. Robot. 2011, 27, 1107-1117.

10. Koh, K.H.; Sreekumar, M.; Ponnambalam, S.G. Hide details Hybrid electrostatic and elastomer adhesion mechanism for wall climbing robot. Mechatronics 2016, 35, 122-135.

11. Liu, R.; Chen, R.; Shen, H.; Zhang, R. Wall climbing robot using electrostatic adhesion force generated by flexible interdigital electrodes. Int. J. Adv. Robot. Syst. 2013, 10, 36.

12. Beardsley, P. VertiGo a Wall-Climbing Robot Including Ground-Wall Transition. 2015. Available online: www.disneyresearch com/publication/vertigo/ (accessed on 29 December 2015).

13. Schmidt, D.; Berns, K. Climbing robots for maintenance and inspections of vertical structures-a survey of design aspects and technologies. Robot. Auton. Syst. 2013, 61, 1288-1305.

14. Chu, B.; Jung, K.; Han, C.S.; Hong, D. A survey of climbing robots: Locomotion and adhesion. Int. J. Precis. Eng. Manuf. 2010, 11, 633-647.

15. Xu, F.Y.; Wang, X.S.; Jiang, G.P. Design Method and Analysis for Wall-climbing Robot based on Hooked-claws. Int. J. Adv. Robot. Syst. 2012, 9, 1-12.

16. Sattar, T.P.; Rodriguez, H.L. Climbing ring robot for inspection of offshore wind turbines. Ind. Robot Int. J. 2009, 36, 326-330.

17. Fauroux, J.-C.; Morillon, J. Design of a climbing robot for cylindro-conic poles based on rolling self-locking. Ind. Robot Int. J. 2010, 37, 287-292.

18. Yazdani, B.; Ahmadabadi, M.N.; Harati, A.; Moaveni, H.; Soltani, N. Design and development of a pole climbing robot mechanism. In Proceedings of the Mechatronics and Robotics, Aachen, Germany, 13-15 September 2004.

19. Baghani, A.; Ahmadabadi, M.N.; Harati, A. Kinematics Modeling of a Wheel-Based Pole Climbing Robot (UT-PCR). In Proceedings of the IEEE International Conference on Robotics and Automation (ICRA), Barcelona, Spain, 18-22 April 2005; pp. $2099-2104$.

20. Gui, P.; Tang, L.; Mukhopadhyay, S. A Novel Robotic Tree Climbing Mechanism with Anti-Falling Functionality for Tree Pruning. J. Mech. Robot. 2018, 10, 014502.

21. Gui, P.; Tang, L.; Mukhopadhyay, S. A Novel Design of Anti-falling Mechanism for Tree Pruning Robot. In Proceedings of the IEEE 10th Conference on Industrial Electronics and Applications (ICIEA), Auckland, New Zealand, 15-17 June 2015; pp. 812-816. [CrossRef]

22. Urdaneta, M.; Garcia, C.; Poletti, G.; Ejarque, G.; Saltaren, R.; Aracil, R. Development of a novel autonomous robot for navigation and inspect in oil wells. CEAL 2012, 14, 9-14.

23. Franko, J.; Du, S.; Kallweit, S.; Duelberg, E.; Engemann, H. Design of a Multi-Robot System for Wind Turbine Maintenance. Energies 2020, 13, 2552.

24. Xiong, Y.; Tuononen, A. Rolling deformation of truck tires: Measurement and analysis using a tire sensing approach. J. Terramech. 2015, 61, 33-42. [CrossRef] 